\title{
Low Nicotine Content Cigarette
}

National Cancer Institute

\section{Source}

National Cancer Institute. Low Nicotine Content Cigarette. NCI Thesaurus. Code C162685.

A cigarette with a nicotine content around $1.3 \mathrm{mg}$ nicotine/g tobacco. 